International Review of Research in Open and Distributed Learning Volume 17, Number 3

April - 2016

\title{
Enhancing Student-Student Online Interaction: Exploring the Study Buddy Peer Review Activity
}

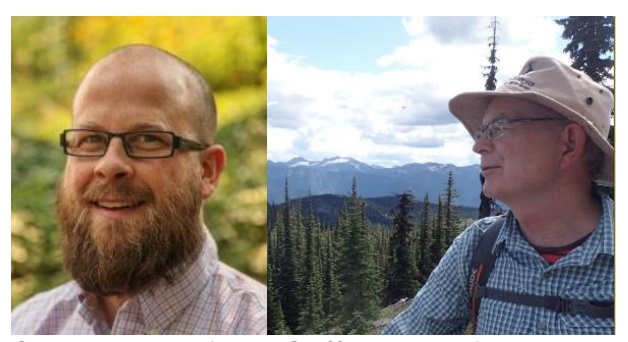

Colin Madland ${ }^{1}$ and Griff Richards ${ }^{2}$

${ }^{1}$ Thompson Rivers University, Canada, ${ }^{2}$ Athabasca University, Canada

\begin{abstract}
The study buddy is a learning strategy employed in a graduate distance course to promote informal peer reviewing of assignments before submission. This strategy promotes student-student interaction and helps break the social isolation of distance learning. Given the concern by Arum and Roksa (2011) that student-student interaction may be distracting from instead of contributing to academic achievement it was felt important to examine the way peer interaction can contribute to learning in a well-structured collaborative learning activity. This mixed-methods study $(n=31)$ examined both quantitative and qualitative aspects of student perceptions of the study buddy activity. While quantitative findings regarding depth of processing were inconclusive due to the small and homogeneous sample, qualitative analysis showed very high levels of learner support for the activity as well as evidence that the activity encouraged learners to approach their learning with greater depth. $88 \%$ of study buddies said they found the activity well worth their time, and would recommend it for other graduate courses. It is thought with greater scaffolding, the quality of buddy feedback might be improved. The few who did not appreciate the activity felt let down by a lack of buddy commitment to the process.
\end{abstract}

Keywords: interaction, cooperative learning, critical thinking, study buddy, approaches to learning, learning design 


\section{Introduction}

From the Socratic dialogue of the ancient Greeks to the academic debates characterizing the advent and modernization of universities, one of the defining features of quality educational experiences has been interaction. Interaction is so central to the learning process that it is difficult to imagine a learning experience that does not involve some sort of interaction between new ideas and old to create an updated mental model through cognitive restructuring (Dewey, 1916).

Several theorists have identified different modes of interaction in educational contexts such as those between and among students, teachers, and the content that is to be learned (Anderson, 2003a; Anderson, 2003b; Bernard et al., 2009; Kanuka, 2011; Moore, 1989). Anderson (2003a) introduced a model that includes the three primary forms of interaction: student-student, student-teacher, and student-content. Their model also expands to include other forms, such as teacher-content interaction, which are important, but beyond the scope of this investigation (Figure 1).



Figure 1. Modes of interaction in distance education from Anderson (2003a).

Moore and Kearsley (2005) note that teachers often interact with students in order to stimulate interest and motivation to learn as well as help students apply their learning. Anderson (2003a) points out that student-teacher interaction is generally very expensive and the cost increases with increasing numbers of 
students, making it generally the least scalable mode of interaction. Ally (2008) notes that while online distance learning is always mediated by some sort of technology, digital or otherwise, the learning that happens cannot be attributed to the technology itself, but rather to the activities and strategies designed into the learning materials as well as the instructor's guidance and direction of the learning activities.

Student-content interaction is a primary reason why formal educational systems exist. "Content" is simply the subject matter that is to be learned (Moore \& Kearsley, 2005). Content can be seen as being either external to the learner, in the case of a learner studying the process of plate tectonics; or it can be internal to the learner, in the case of a learner examining his or her own assumptions about a topic. In higher education, student-content interaction can be scaled up quite dramatically, as evidenced by the large enrolments in some required undergraduate, lecture-based classes at large universities. On the other hand, as class size increases, effective student-teacher interaction becomes more difficult.

In correspondence education, when content was delivered by post, there was little possibility for students to interact with each other (Anderson, 2003b; Moore \& Kearsley, 2005). Advances in online communication technologies have opened up significant opportunities for students to interact with each other synchronously through web-conferencing or text chat, and asynchronously through discussion forums, email, and text messages on mobile devices, as well as through social networking software. As with student-content interaction, student-student interaction is extremely scalable, but care must be taken to ensure the engagement has educational value rather than being simply social in nature.

While Kuh (2003) has strongly advocated social engagement of learners as an important retention factor, on-campus student-student interaction has come under scrutiny by Arum and Roksa (2011) for failing to engage learners academically. They claim that student-student social interaction does not necessarily promote academic achievement and more often distracts from learning. This challenges faculty and instructional designers to ensure that student-student learning activities are goal-focused and robustly constructed to promote learning. Among the best guidelines for this come from the area of cooperative learning (Johnson \& Johnson, 1999a; Johnson \& Johnson, 2002; Slavin, 1980; Slavin, 2011).

This study focused on the student-student mode of interaction in online distance learning. It investigates the nature of student-student interactions in the study buddy peer review activity and how the activity might be structured to support and facilitate critical thinking, discourse, and meaningful engagement.

\section{Interaction Equivalency Theorem}

In 2003, Anderson proposed the Interaction Equivalency Theorem:

Deep and meaningful formal learning is supported as long as one of the three forms of interaction (student-teacher; student-student; student-content) is at a high level. The other two may be offered at minimal levels, or even eliminated, without degrading the educational experience.

High levels of more than one of these three modes will likely provide a more satisfying 
educational experience, though these experiences may not be as cost or time effective as less interactive learning sequences. (Anderson, 2003a)

Bernard et al. (2009) found empirical support for Anderson's theorem in a meta-analysis of research articles related to different modes of interaction in distance education. Examining 74 reports that fit their criteria and categorizing them according to student-student, student-teacher, or student-content interaction treatments, they found that there was an average effect size of +0.38 , indicating that the interaction treatments had a moderate, positive effect on achievement and that the greatest effects were found to be associated with student-student (+0.49) and student-content (+0.46) interactions, which were considered to be not significantly different from each other. The smallest effect size was for studentteacher (+0.32) interactions. They also found that when the strength of a particular interaction treatment increased, the average effect size also increased, suggesting that higher quality interactions generally lead to better achievement, a finding that supports Anderson's equivalency theorem.

Bernard et al. (2009) suggested that the use of cooperative learning techniques to promote positive interdependence (Johnson \& Johnson, 1991) and personal accountability in structured learning activities was one way for designers to ensure high-quality interactions and that there should be a strong emphasis on deep interaction with content to ensure that integrative learning is supported.

\section{Cooperative Learning}

Cooperative learning is the pedagogical practice of structuring learning activities so that dyads or small groups of students work together in order to achieve the stated goal of the activity (Johnson \& Johnson, 1999a; Slavin, 1980; Slavin, 2011). Slavin (1980) contrasts cooperative activities with competitive and individualistic learning activities. Competitive activities are structured in such a way that the success of one student necessitates the relative failure of another student, whereas individual activities are those structured so that the achievement of one student has no effect on the achievement of other students. In comparison, cooperative activities are structured so that the success of one student is dependent upon and promotes the success of others. While some faculty may contend that they encourage or require students to work with partners and groups on a regular basis, a review of the literature on cooperative learning shows that unstructured group work is not as effective at improving achievement when compared to wellstructured cooperative learning activities (Johnson \& Johnson, 1999a; Johnson, Johnson, T, \& Holubec, 1994; Johnson, Johnson, \& Stanne, 2000).

To distinguish between unstructured group work and cooperative learning, researchers (Johnson et al., 1994; Johnson \& Johnson, 1999b, Jones \& Jones, 2008) have identified five key characteristics of wellstructured cooperative learning activities: positive interdependence, group and individual accountability, promotive interaction, appropriate social skills, and group processing.

Positive interdependence is the result of each student's individual success being dependent upon the success of the group. To structure positive interdependence, it is essential that each student have a unique and necessary role in the group. 
Group accountability exists when the teacher assesses the performance of the entire group.

Individual accountability is the characteristic that prevents some group members from benefiting from the work of others without offering any contributions.

Social and inter-personal skills coaching is often necessary when learners are immature or have little prior experience in cooperative learning.

Group processing has the group evaluate and reflect on their effectiveness as a group with an eye to improving future work.

Activities with individual accountability require the assessment of individual contributions. For example, the group score on an assessment should be based on what each member scores on the assessment individually. If the group were to be assessed on a single submission, then it would be much easier for one or several of the group members to relax while one or a few do the majority of the work. Johnson and Johnson include the idea of promotive interaction as also being critical to the success of cooperative learning groups. By promotive, the Johnsons mean that the interactions between group members must support the learning activities of each group member. There must be an ethos of support and encouragement between group members. They argue that the interaction must be face-to-face, but as previously noted, technological advances in the years since Johnson and Johnson originally published their recommendations now allow remote students and teachers to interact in virtual face-to-face settings.

Slavin (2011) identifies four possible mechanisms by which well-structured cooperative learning activities might affect student achievement:

- increased learner motivation,

- increased social cohesion,

- developmentally appropriate challenges, and

- increased cognitive elaboration.

The first two processes that seem to be at work are related to student motivation. It is possible that working cooperatively provides motivational incentive for students to learn the material carefully because they want to get good grades, or that cooperative learning activities promote social cohesion, leading to positive social pressure from peers. Both of these mechanisms rely on the presence of positive interdependence in the activity. Two other possibilities are based more on the cognitive changes that are enabled by cooperative activity. The first is the suggestion that working with peers is developmentally advantageous as there are many opportunities for students to be challenged within their zones of proximal development (Vygotsky, 1978) by their peers who are just slightly more capable. The other is based on the long-held notion from cognitive psychology that in order for students to retain new information, they must restructure or elaborate on their previous understandings. One effective method of promoting that 
cognitive elaboration is to have a student explain a concept to a peer.

In Slavin's model, the learning activity design must promote positive interdependence, i.e. the achievement of the group depends upon the contribution of all group members. When positive interdependence is present, Slavin proposes that group members are more motivated to learn for personal and social reasons and that there is a greater sense of social cohesion. Furthermore, increased motivation to learn and increased social cohesion are mutually reinforcing. These personal and social drivers then provide the conditions necessary for group members to engage in deeper approaches to learning, where they explain concepts and misconceptions, form and defend positions, and debate the merits of ideas.

It is also important to recognize the importance of intellectual conflict between group members. Johnson and Johnson (1999b) contend that the process of presenting and actively defending a view and developing and presenting a carefully reasoned response to legitimate criticism, in their words, intellectual conflict, is highly desirable if the goal of the learning activity is to promote critical thinking and clear communication. If such intellectual conflict is handled appropriately by group members who have been taught and have practiced the interpersonal and group skills necessary to argue constructively, then teachers can expect to see reduced levels of self-confidence in students' views leading to a continued search for information and further cognitive elaboration and practice of critical thinking skills. The Johnsons also note that students working alone, and this author would add, especially those working alone in online distance learning contexts, do not have the opportunity to hone their ideas against those of other students.

\section{Surface Versus Deep Approaches to Learning}

According to Biggs et al. (2001), two categories of factors precede learning tasks. First, students will approach learning tasks according to their preferences, abilities, and prior knowledge. Second, teachers will design the learning task in alignment with the course objectives, style of assessment and/or institutional priorities. These two sets of factors have a role in influencing how a particular student will approach a particular task. Both of these categories of factors influence the students' actions in relation to the learning task, and it is these actions, or approaches to learning, that determine how well the students attain the learning objectives. According to Biggs and Tang (2011), students can take either a surface or a deep approach to a learning task.

Students relying on low-level cognitive skills for tasks that require high-level cognitive skills demonstrate a surface approach. Students using a surface approach are more concerned with getting the learning task out of the way quickly to meet the requirements with minimum effort. They memorize isolated facts when an understanding of how ideas are connected is necessary (Ramsden, 1992).

Deep approaches to learning, according to Biggs and Tang (2011), are characterized by the appropriate use of high-level cognitive skills for tasks that require them. Students taking a deep approach seek to understand ideas in context and apply their learning to other concepts. They actively consider their own questions and seek answers related to the idea. In short, students taking a deep approach to their learning 
are doing the things required of critical thinkers (Brookfield, 1987; Hendrickson, St. Amant, Hawk, O’Meara, \& Flage, 2008).

In the present study, the idea of approaches to learning was considered to be a proxy for what might otherwise be called critical thinking and a precursor to student acheivement. As Shuell stated in 1986,

If students are to learn desired outcomes in a reasonably effective manner, then the teacher's fundamental task is to get students to engage in learning activities that are likely to result in their achieving those outcomes. It is important to remember that what the student does is more important than what the teacher does. (p. 429)

Garrison and Cleveland-Innes (2005) provide a strong rationale for the argument that instructors who want their students to think critically in their discipline of inquiry must be intentional in how they design the interactions in their courses. Using Garrison, Anderson, and Archer's (2000) Community of Inquiry model as their foundation, Garrison and Cleveland-Innes (2005) used the Study Process Questionnaire (Biggs et al., 2001) to measure how students in four graduate-level courses approached their learning over the duration of the course. They found that course design and teacher presence were critical to encouraging the online learners to take a deep, meaningful approach to learning. In comparing the courses they found a profound shift from surface towards deep levels of learning only in the course that had learning activities specifically designed to engage students in critical thought. They concluded that in order for deep, meaningful learning to take place, attention must be paid to structuring quality interactions in the design and facilitation of online distance learning environments, rather than simply increasing the quantity of interactions.

\section{The Study Buddy Activity}

The study buddy is a voluntary learning activity in a graduate-level, asynchronous, online distance learning course in instructional design offered by Athabasca University. MDDE 604, Instructional Design in Distance Education, is a paced cohort, project-based course that requires students to, over the course of four assignments, propose, design, and create a unit of instruction. MDDE 604 is delivered over 13 weeks through Moodle ${ }^{\mathrm{TM}}$. Assessment is based on completion of four mandatory and sequential assignments, three small group conferences, and the optional study buddy activity. Students who complete the requirements of the optional study buddy activity can earn up to $5 \%$ bonus to their final grade.

The study buddy was introduced in 2001, when the second author noted systemic shortcomings in the assignments, particularly academic writing, reasoning and completeness. It was hoped that introducing a voluntary peer review activity would help trap errors and omissions in a formative setting and provide learners an opportunity to submit the best work possible. Over the years, a few guidelines have been introduced. For example, those who consider themselves "bunnies", who like to complete their work well ahead of schedule, and those who consider themselves "bears", who typically work closer to assignment deadlines, are encouraged to find partners who are similar to themselves to avoid conflict related to the timing of the peer review process. The peer exchange is recommended three days before the assignment 
due date. Furthermore, partners need to be self-selected by the third week in the course. The bonus points are an incentive to enlist learners who might otherwise be unwilling or reluctant to reach out to others in the course. To earn the full $5 \%$, buddies must review their partner's four assignments and submit a short 1-2 page reflection on their buddy experience. While the buddy reports have been overwhelmingly supportive of the activity, no comprehensive study of the activity has been made. The focus of the current study was to look at the impact of the study buddy compared with participants' approaches to learning and to analyze their qualitative appreciation of the experience.

\section{Purpose of the Study and Research Questions}

The purpose of this study was to explore the study buddy activity as an instructional design that uses wellstructured student-student interaction to promote deeper approaches to learning as well as valuable social engagement. Additionally, following Slavin's (2011) integrated model of cooperative learning, the study explored various ways in which the study buddy activity led to increased social cohesion and motivation, provided developmentally appropriate learning challenges, and promoted cognitive restructuring. Finally, the study explored participants' perceptions related to the logistics and structure of the study buddy activity.

The investigation explored the following questions related to the study buddy activity:

1. Do online graduate students who participate in a structured study buddy activity tend to use deep approaches in their learning?

2. As a cooperative learning activity, does the study buddy activity provide sufficient scaffolding to promote deep approaches to learning?

3. In what ways do students find value in the study buddy activity?

A more complete discussion of the study can be found in the first author's thesis (Madland, 2014).

\section{Method}

\section{Participants}

Participants $(n=31)$ in the study represented a convenience sample, as only one course that utilized this study buddy strategy was available to the researcher. A total of 101 students were invited to participate in the study; 26 in the Fall (September - December) 2012 term, 25 students in the Winter (January - April) 2013 term, and 50 students in two classes in the Spring (May-July) 2013 term. Approximately 80\% of students in the four classes engaged in the study buddy activity and a total of 31 subjects participated in the study; 25 were participants in the study buddy activity and 6 were non-participants. The response rate was $30.6 \%$ over the three terms of data collection. All four classes had the same instructor. 


\section{Procedure}

The design used in this investigation was a 2-phase QUAN/QUAL concurrent triangulation model (Creswell, 2009, p. 213). The rationale for using the mixed methods approach is that the results of the two forms of data analysis could be compared and merged into an integrated analysis which would be stronger than if either a quantitative or qualitative analysis was performed in isolation. This comparison of analyses is known as triangulation or sometimes as a convergent design (Creswell \& Plano Clark, 2010).

While the quantitative analysis showed that most of the participants in the study (all graduate students) used deep approaches to study, further statistical analysis was not possible because of the small sample, consequently, this paper will focus on the qualitative aspects of the study.

\section{Instrumentation}

The first step of this investigation gathered both quantitative and qualitative data through a survey. Data were gathered using Biggs, Kember \& Leung's (2001) Revised Two-Factor Study Process Questionnaire (R-SPQ-2F), which was supplemented with additional sections designed to elicit responses related to how students perceived the effect of the study buddy activity on their approaches to learning and how they perceived the study buddy activity itself. Biggs, Kember \& Leung (2001) calculated Cronbach's alpha for each of the scales of the R-SPQ-2F as 0.73 for the deep scale and 0.64 for the surface scale.

Open-ended questions were interspersed throughout the quantitative items on the survey. These items were designed to elicit explanations of the participants' choices on the quantitative items in order to understand their experiences with the study buddy activity. Responses to these open-ended questions formed the qualitative data for the study. The study was proposed to include the possibility of semistructured interviews, but it was determined after the analysis of the responses to the open-ended questions that the data obtained were sufficient to satisfy the exploratory nature of the objectives of the study.

The survey was divided into four sections corresponding to the three research questions and the fourth to gather data from subjects who did not participate in the study buddy activity. Prior to the main sections of the survey, participants were asked whether or not they participated in the study buddy activity. Those who participated were automatically directed to complete the first three sections, and those who did not participate were automatically directed to complete only the first section and the final section.

\section{Results}

\section{Quantitative Analysis}

PASW Statistics ${ }^{\mathrm{TM}}$ was used to calculate the t-test, basic descriptive statistics, and frequencies on the quantitative data. Due to the exploratory nature of this investigation, the small sample size and the very 
small size of the non-participant group $(n=6)$, further in-depth statistical analyses would have been unjustified.

\section{Question 1: Do online graduate students who participate in a structured study buddy activity tend to use deep approaches in their learning?}

Almost all the subjects (graduate students) identified as already using deep learning approaches and there were no differences between participants and non-participants so there was no way to test for additional effect from the study buddy activity.

\section{Question 2: As a cooperative learning activity, does the study buddy activity provide sufficient scaffolding to promote deep approaches to learning?}

The second research question was reflective of the exploratory nature of the study in that there was no expectation of a difference between any of the four classes of participant groups in the study. Consequently, data were described rather than compared.

A key structural component of the study buddy activity is the description that the instructor uses to characterize different types of students. The second author uses "bunnies" to describe those students who typically prefer to get their work done early and "bears" to describe those who usually finish their work at the last minute. He recommends that bunnies pair with bunnies and bears pair with bears to avoid the conflicts that may arise in a partnership with one who wants to complete the work early and the other who procrastinates and pushes the work to the deadline.

The importance of partner compatibility was an interesting theme recurring throughout the quantitative and qualitative findings. Of the three participants who described themselves as "more of a bear", all three indicated that their partner had a different profile than their own, yet only one of the three reported having a bad experience in the study buddy activity.

Three participants reported having a bad experience with the study buddy activity, and all three had partners with different profiles, however, there were another four who reported having a good experience while their partners had a different profile. Furthermore, one of the participants who had a bad experience reported that their partner suddenly disengaged from the activity without notification.

\section{Question 3: In what ways do students find value in the study buddy activity?}

Given the finding from the quantitative analysis that the study buddy activity did not significantly promote deeper approaches to learning, the third research question in this investigation became more important in order to determine the characteristics of the study buddy activity and its value for participants. A clearer understanding of how study buddy participants valued the activity may provide insight into how the activity could be improved to increase its effect on student approaches to learning.

Survey items were designed to align with the four ways in which cooperative learning activities support improved learning: 
- increased learner motivation,

- increased social cohesion,

- developmentally appropriate challenges, and

- increased cognitive elaboration (Slavin, 2011).

Survey results, shown in Table 1, revealed that participants credited the study buddy activity with providing a high level of social cohesion (mean score $=4 \cdot 12 / 5$ ).

Table 1. Alignment with Slavin's model of cooperative learning.

\begin{tabular}{ll}
\hline Category & Mean \\
\hline Learner Motivation & 3.62 \\
\hline Social Cohesion & 4.12 \\
\hline Developmentally Appropriate Challenges & 3.70 \\
\hline Cognitive Restructuring & 2.92 \\
\hline
\end{tabular}

Of particular interest was the finding that nearly all of the participants (96\%) indicated that they wanted to help their partner, suggesting that one way to enhance the effect of cooperative learning activities is to capitalize on students' altruism, i.e., their desire to help others in their class or group. The next most valued category was developmentally appropriate challenges (mean score $=3.70$ ), which reflected the importance of having partners who were both willing and able to provide meaningful feedback within their partner's zone of proximal development.

The motivational perspective followed closely behind (mean score=3.62), followed lastly by the cognitive restructuring perspective (mean score=2.92). A significant reason that the cognitive restructuring score was the lowest was the fact that very few participants in the study buddy activity reported intellectual conflict with their partners.

The final section of the survey asked whether participants would recommend the study buddy activity in other contexts. Most (88\%) of the participants would recommend the activity for MDDE 604 (the course in which the participants were enrolled), for other courses in the M.Ed. program, and as a general distance education strategy. Only one respondent (6\%) did not recommend the study buddy activity.

The non-participants in the study buddy activity $(n=6)$ reported that they understood from the instructions what would be required to earn credit for the study buddy activity and that they primarily decided to not participate because of the time involved in the activity.

\section{Qualitative Analysis}


Qualitative data were analyzed using a generalized method that was loosely based on phenomenological procedures as described in Creswell (2007). Written responses to the open ended questions in the survey totaled approximately 4000 words. These were compiled onto a spreadsheet and imported into qualitative data analysis software (NVivo ${ }^{\mathrm{TM}}$ ) to be coded. The researcher developed a list of non-overlapping significant statements which were then grouped into themes. The first round of coding resulted in 227 significant statements organized into 65 minor and four major meaning units or themes. This list was reduced to 18 minor and four major themes by eliminating statements that were deemed to be less relevant to the research questions.

The four major themes focused on the following:

- the student's approach to learning and the cognitive skills generally employed by students in the course;

- the value derived from the study buddy activity;

- recommendations about the structure of the study buddy activity;

- the experience of those who chose not to participate or the negative experiences of participants in the study buddy activity.

\section{Approach to Learning}

Although the quantitative analysis showed no significant difference between the approaches taken by participants and non-participants in the study buddy activity, there was evidence in the qualitative data that the students in the course already tended to take a deep approach to their learning by utilizing the high-level cognitive skills associated with deeper approaches, such as extension and application, both of which are indicative of critical thinking. For example, one student wrote "I also buy books or download research articles that enrich or contradict the course readings." Another student wrote "[I] try to explore as much material as I feel is needed to make up my own conclusion/opinion on the issue."

Many students also reported that they try to extend their understanding of course concepts by seeking alternate and other recommended resources. One student wrote "[I] look up alternate sources to the material in books/articles from previous courses and in the AU library"; another stated, "[I undertake] further exploration of the same key words/topics on the internet to find the latest information if readings seem a bit out of date."

Another key strategy described by students in the course was that of seeking to apply course concepts to their own work context. For example, a student wrote, "I approached each topic with these questions: 'What here applies to me and to my work?' 'How might this help me with my work?'” Another student reported, "Being able to relate what I read to work is enlightening."

Among the features that scholars have identified to describe critical thinking is that the learners must be 
willing to engage in the process of critical thinking, that they examine justifications, and consider alternate viewpoints (Bailin, Case, Coombs, \& Daniels, 1999; Brookfield, 1987). The participants in this study clearly demonstrated a willingness to seek out readings to enrich the course readings, as well as contradictory viewpoints. By doing so, they were considering the rationale for their own opinions in light of the opinions stated in the course readings, an important feature of critical thinking.

However, missing from these activities was the opportunity for students to defend their views against others who actively advocated for a different view. Extending knowledge through seeking alternative or challenging articles, books or other media, and applying concepts to relevant contexts are certainly positive, but these activities could be seen as being relatively passive, risk-free instances of critical thinking in comparison with actively challenging another person's ideas. As discussed in the next section, participants in the study buddy activity reported that the activity pushed them to do more than simply seek out static resources and actually consider alternative viewpoints.

\section{Value of the Activity}

Participants in the study buddy activity reported that the activity was valuable to them because of the social connection it provided in an otherwise lonely learning environment, the benefit of an alternate viewpoint, and the motivation to complete the work on time.

The relationship between the social benefits of the activity and improved learning was supported by reports from participants that the activity provided what Slavin (2011) calls peer motivation to study. Participants felt that they would be letting their study buddy partner down if they did not get their work completed in enough time to allow for peer review and revision. As one participant noted, "I was motivated to complete work in a timely manner so that my "buddy" could review my work without being rushed". Another indicated, "[We] knew there was someone out there who depended on us to have work completed on time." The peer motivation was not only focused on getting the work done on time, however; one participant reported: "[my study buddy] also helped me stay in the course because I had committed to being a peer reviewer" suggesting that, for this student, the activity was a factor in her decision to persist in the course because of her promise to her partner.

With respect to promoting deep approaches to learning and critical thinking skills, participants in the activity indicated that, beyond the deep strategies they already employed, they also valued the opportunity for collegial exchange and debate with their partner's alternate viewpoint. This type of interaction went beyond the search for alternate viewpoints in the literature, providing a situation where the alternate viewpoint was coming from someone they knew, trusted, and respected, as well as an opportunity to incorporate their partner's ideas into their own. For example, one participant reported, "[I] got to see another's work that caused me to consider an alternative point view and to contribute my perspective of their work." So, it was not only the feedback that they received from their partner that was valuable to participants, but also the ability to read their partner's work.

Participants reported that being exposed to an alternate viewpoint from a trusted peer and then having to 
provide collegial and constructive feedback helped them to improve their reasoning with respect to course concepts. One participant noted, "At the same time I found that at the beginning just by trying to help improve assignments of my study buddy and talking about them helped me to improve my thinking and logic." A second participant wrote, "[My partner was] even better at seeing where I needed to expand an argument and where I could cut back on unnecessary detail." Another student appreciated having a partner to whom he could direct his explanations as indicated in the following:

My study buddy became my audience as I was writing - I was writing to explain the material to her. In turn, she was able to point out gaps in my reasoning, to question what I meant and to help me sharpen my ideas and arguments.

\section{The Structure of the Activity}

Garrison and Cleveland-Innes (2005) argue that the design of the learning environment is a very significant factor in whether or not learners will take a deep approach to their learning and utilize critical thinking skills. In other words, the learning activities must be structured to encourage learners to take a deep approach. In view of this recommendation, participants were asked whether they thought the study buddy activity should be mandatory and structured or voluntary and student driven. Their responses were evenly divided between the two options.

\section{Negative Experiences and the Views of Non-Participants}

A key to understanding the full complexities of a phenomenon is to consider the views of those who have views contrary to the prevailing view, an idea supported by the literature on critical thinking (Brookfield, 1987). Study buddy participants who had a negative view of the activity were very clear that the greatest frustrations occurred when there were inequities in either partner's motivation or in the quality and depth of the feedback received. Others noted that the extra workload associated with the activity was, at times, problematic.

\section{Summary of the Qualitative Analysis}

Online distance learning is an often isolating and lonely experience and many participants are mid-career professionals returning to school after an extended absence. It was previously common for students in MDDE 604 at Athabasca University to struggle with writing at an appropriate academic level, so the instructor decided to incorporate a small-scale peer review and feedback mechanism to provide academic and social support for students. When surveyed for their views on the study buddy activity, students' responses fit into four major themes: (1) approach to learning and cognitive skills, (2) the value of the activity, (3) the structure of the activity, and, (4) negative experiences and the views of non-participants.

Students in MDDE 604 demonstrated an existing willingness to engage in deeper approaches to learning and utilize cognitive skills indicative of critical thinking, such as applying their learning to their work outside the course and extending their understanding by seeking out alternative opinions in journals and books. Those who participated in the study buddy activity indicated that the activity encouraged them to 
go beyond these critical thinking activities and engage in active discussion with their partner who provided an alternate viewpoint. These participants reported that their engagement with these deeper cognitive skills improved their reasoning and the quality of their work. They also reported that they felt very supported and connected as a result of engaging with a trusted and respected peer through the activity and that they were more motivated to complete their work far enough ahead to allow for the peer review process.

Students were divided in their opinions of whether the activity should be voluntary or mandatory and often used the same rationales to come to opposing conclusions on the question. They were united in their view that the activity must allow for negotiation between study buddy partners with respect to the timing of their submissions to each other.

Those who had a negative experience with the activity reported that their frustrations stemmed from incongruent motivations, where one partner was seen to be doing the minimum required to pass the course, or from inadequate or superficial feedback from their partner. While participants noted that the extra workload was significant, they reported that it was worthwhile. Those who chose not to participate in the activity cited a desire to work alone, the time involved in the activity, and the fear of getting a lazy partner as reasons for opting out.

\section{Discussion/Conclusions}

Results of the quantitative and qualitative analyses indicated that participants in the study buddy activity were very socially engaged with their partner as a result of the activity and that the activity helped participants to deepen their approach to learning. While there was no significant difference detected in the quantitative analysis with respect to students' approach to learning (participants in this study typically used deep approaches, even those who did not participate in the study buddy activity), the qualitative findings showed that participants in the study buddy activity engaged in skills that required greater levels of cognitive effort. For example, many students in the course reported consulting recommended readings and searching for alternative views in published literature, but those who participated in the study buddy activity also reported having conversations with their study buddy partners about the course content and working to help each other understand the material in greater depth. This combination of social engagement and academic rigour is evidence that cooperative learning activities like the study buddy activity have a positive influence on student achievement.

Participants were divided on whether the study buddy activity should be mandatory or voluntary, but a clear majority of participants indicated they would participate in a similar activity again and would recommend the activity for students in other graduate-level courses. One of the most significant barriers to participation in the activity was the reticence with which many students approach group activities, usually based on past experiences that ended poorly. 
Finally, finding that $88 \%$ of study buddies would recommend the activity is a result that supports continuing the practice. Those who participated in the study buddy activity were clear that the activity and the connection that they developed with their partner was a significant source of emotional and social support despite the oft-cited loneliness of studying in an online setting. This feeling of being supported led to the development of a trusting and respectful context in which the partners could ask questions about course content and receive constructive and sometimes corrective feedback about their ideas.

\section{Recommendations}

Findings from this exploratory investigation suggest the following recommendations with respect to using the study buddy activity or other similar cooperative learning strategies in online distance education:

The study buddy activity can be easily implemented in online higher education. Faculty and instructional designers should consider adding this and other structured cooperative learning strategies to their courses.

Given that a significant barrier to participation in the study buddy activity was the fear of ending up with a poor partner as well as the lack of consensus on whether the activity should be voluntary or mandatory, a recommended action would be to keep the activity voluntary with a small incentive for providing evidence of participation.

Faculty who introduce the study buddy should ensure that the students understand the potential benefits from participation such as the opportunity to consider alternate viewpoints, consider their own views more critically, and the sense of social support that can be enjoyed from working with a trusted and respected peer.

One of the reasons why a few participants had a negative experience with the activity was that they received inadequate or superficial feedback. This concern, combined with the under-representation of the idea of the activity as a peer review process, suggests that the activity be proposed to students along with additional directions and perhaps a template to guide the peer review process.

In summary, while additional studies will need to be conducted to determine the extent of any shift in approaches to learning. The study buddy strategy appears to be a successful and appreciated learning activity in graduate courses. The social cohesion it brings provides important supports for learners at a distance. Faculty and instructional designers would be wise to consider other opportunities for promoting learning through this strategy.

\section{References}

Ally, M. (2008). Foundations of educational theory for online learning. In T. Anderson (Ed.), The theory 
and practice of online learning (2nd ed., pp. 15-44). Athabasca: Athabasca University.

Anderson, T. (2003a). Getting the mix right again: An updated and theoretical rationale for interaction. International Review of Research in Open and Distance Learning, 4. Retrieved from http://www.irrodl.org/index.php/irrodl/article/view/149/230

Anderson, T. (2003b). Modes of interaction in distance education: Recent developments and research questions. In M. G. Moore \& W. G. Anderson (Eds.), Handbook of distance education. Mahwah, NJ: L. Erlbaum Associates.

Arum, R., \& Roksa, J. (2011). Academically adrift: Limited learning on college campuses. The University of Chicago Press.

Bailin, S., Case, R., Coombs, J. R., \& Daniels, L. B. (1999). Conceptualizing critical thinking. Journal of Curriculum Studies, 31, 285-302.

Bernard, R. M., Abrami, P. C., Borokhovski, E., Wade, C. A., Tamim, R. M., Surkes, M. A., \& Bethel, E. C. (2009). A meta-analysis of three types of interaction treatments in distance education. Review of Educational Research, 79, 1243-1289.

Biggs, J., Kember, D., \& Leung, D. Y. P. (2001). The revised two-factor Study Process Questionnaire: RSPQ-2F. British Journal of Educational Psychology, 71, 133-149. doi:10.1348/000709901158433

Biggs, J., \& Tang, C. (2011). Teaching for quality learning at university: What the student does (4th ed.). New York: Society for Research into Higher Education \& Open University Press.

Brookfield, S. D. (1987). Developing critical thinkers: Challenging adults to explore alternative ways of thinking and acting. San Fransisco: Jossey-Bass.

Creswell, J. W. (2007). Qualitative Inquiry and Research Design: Choosing Among Five Approaches (2nd ed.). Thousand Oaks, CA: Sage Publications. Retrieved from http://www.sagepub.com/booksProdDesc.nav?prodId=Book227517

Creswell, J. W. (2009). Research Design: Qualitative, quantitative and mixed method approaches (3rd ed.). Thousand Oaks, CA: Sage Publications.

Creswell, J. W., \& Plano Clark, V. L. (2010). Designing and conducting mixed methods research (2 ed.). Thousand Oaks, CA: Sage.

Dewey, J. (1916). Democracy and education. New York: The Macmillan Company.

Garrison, D. R., \& Cleveland-Innes, M. (2005). Facilitating cognitive presence in online learning: Interaction is not enough. American Journal of Distance Education, 19, 133-148. Retrieved from 
http://www.informaworld.com/10.1207/s15389286ajde1903_2

Hendrickson, N., St. Amant, K., Hawk, W., O’Meara, W., \& Flage, D. (2008). The Rowman \& Littlefield handbook for critical thinking. Lanham, MD: Rowman \& Littlefield Publishers.

Johnson, D. W., Johnson, R., \& Stanne, M. B. (2000). Cooperative learning methods: A meta-analysis., 17. Retrieved from http://www.tablelearning.com/uploads/File/EXHIBIT-B.pdf

Johnson, D. W., \& Johnson, R. T. (1991). The impact of positive goal and resource interdependence on achievement, interaction, and attitudes. Journal of General Psychology, 118, 341. Retrieved from http://o-

search.ebscohost.com.aupac.lib.athabascau.ca/login.aspx?direct=true\&AuthType=url,ip,uid\&db=a9 $\underline{\mathrm{h} \& \mathrm{AN}=9607102457 \& \text { site }=\text { ehost-live }}$

Johnson, D. W., \& Johnson, R. T. (1999a). Learning together and alone: Cooperative, competitive, and individualistic learning (5th ed.). Boston: Allyn and Bacon.

Johnson, D. W., \& Johnson, R. T. (1999b). Making cooperative learning work. Theory Into Practice, 38, 67-73. doi:10.1080/00405849909543834

Johnson, D. W., \& Johnson, R. T. (2002). Learning together and alone: Overview and meta-analysis. Asia Pacific Journal of Education, 22, 95-105. doi:10.1080/0218879020220110

Johnson, D. W., Johnson, R., T, \& Holubec, E. J. (1994). Cooperative learning in the classroom. Alexandria, VA: Association for Supervision and Curriculum Development.

Kanuka, H. (2011). Interaction and the online distance classroom: Do instructional methods effect the quality of interaction? Journal of Computing in Higher Education, 23, 143-156.

Kuh, G. D. (2003). What We're Learning About Student Engagement From NSSE: Benchmarks for Effective Educational Practices. Change: The Magazine of Higher Learning, 35, 24-32. Retrieved from http://dx.doi.org/10.1080/00091380309604090

Madland, C. (2014). Structured student interactions in online distance learning: Exploring the study buddy activity. Master of Education. Athabasca University.

Moore, M. (1989). Three types of interaction. American Journal of Distance Education, 3, 1-6.

Moore, M., \& Kearsley, G. (2005). Distance education: A systems view (2nd ed.). Belmont, CA: Thomson Wadsworth.

Ramsden, P. (1992). Learning to teach in higher education. London: Routledge.

Slavin, R. E. (1980). Cooperative learning. Review of Educational Research, 5o, 315-342. 
Slavin, R. E. (2011). Instruction based on cooperative learning. In R. E. Mayer \& P. A. Alexander (Eds.), Handbook of research on learning and instruction (pp. 344-360). New York: Routledge.

Vygotsky, L. S. (1978). Mind in society (Luria, A. R., Trans.). Cambridge: Harvard University Press.

\section{Athabasca} University

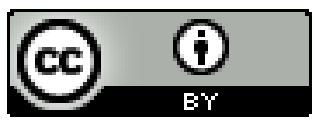

